\title{
THERMODYNAMIC AND KINETIC FEATURES OF THE FORMATION OF AMORPHOUS STATE IN FILMS DURING QUENCHING FROM THE VAPOR STATE
}

\author{
V.F. Bashev", S.I. Ryabtsev, F.F. Dotsenko \\ Oles Honchar Dnipro National University, Dnipro, Ukraine \\ *e-mail: bashev_vf@ukr.net
}

The method of modernized ion-plasma sputtering produced metastable states, including nanocrystalline and amorphous phases in films, even in alloys whose components do not mixed in the liquid state. The effective rate of energy relaxation at different modes of precipitation is theoretically estimated to be $10^{12}-10^{14} \mathrm{~K} / \mathrm{s}$ during ion-plasma sputtering of atoms. On thermodynamic and kinetic states, different active and passive parameters for amorphization during sputtering are analyzed. The receiving expressions are in good agreement with the experimental results and contribute to the determination of further steps to obtain an amorphous state.

Keywords: quenching from the vapor state, ion-plasma sputtering, immiscible alloys, nanocrystalline structure, amorphous phases.

Received 08.06.2021; Received in revised form 25.07.2021; Accepted 15.08.2021

\section{Introduction}

Interest to materials based on components with a very limited mutual solubility in the liquid state has recently increased significantly [1-4]. The peculiarities of such systems include: a large difference in the specific gravity of the components, the presence of a monotectic transformation, a tendency to exfoliation in the liquid state in a wide temperatureconcentration interval which unambiguously indicates on high positive heat of mixing of the alloy components. These factors significantly complicate the use of immiscible components in industry and high technology. However, the application of extremely nonequilibrium conditions for obtaining or processing a material allows us to overcome the effects of positive enthalpy of mixing and to obtain a new class of promising materials. It is also known that the quenching process from a liquid state with cooling rates of $10^{6}-10^{8} \mathrm{~K} / \mathrm{s}$ is accompanied by the appearance of high internal pressures, often leading to the formation of high-pressure phases [5]. The effective rate of energy relaxation during ion-plasma sputtering of atoms is theoretically estimated to be $10^{12}-10^{14} \mathrm{~K} / \mathrm{s}$.

This makes it possible to speak of quenching from the vapor state and opens the possibility of the appearance of high-pressure phases even during ion-plasma sputtering. All this and a many of immiscible systems (about 200 systems of metal-metal type) determine the relevance and prospects of research of a new class of materials for the industry. To date, sufficiently many single-phase alloys have already been obtained in systems of immiscible components characterized by anomalously large positive mixing energy by different methods, primarily quenching from the vapor phase, amorphous phases and highly supersaturated solid solutions [6-8].

The purpose of this work was to determine the effect of the extremely high cooling rates achieved in the modernized ion-plasma sputtering method and thermodynamic and kinetic features on formation of amorphous state in alloys, whose components practically do not mix even in liquid state. It is known that in systems with positive mixing energy the energy barriers for the formation of homogeneous structures are rather high [2]. To overcome them, it is necessary that the kinetic energy of atoms falling on the substrate exceeds the height of these barriers.

\section{Results and their discussion}

The nonequilibrium condensation of substances from vapor is influenced by a few thermodynamic and kinetic parameters: free path, entropy jump, rate of temperature 
relaxation on the substrate, rate of concentration change [1,2]. Each of these parameters affects the formation of the amorphous state, therefore, for more convenient control of this process, it is useful to reduce these parameters into a single criterion. It was noted in [3] that adhesion forces act above the substrate surface, capable of forming quasicrystalline structures with a density of atoms and gas molecules of $\sim 10^{29} \mathrm{~m}^{-3}$, in which at a temperature of $300 \mathrm{~K}$ the bonding forces between atoms are very weak. When metal atoms approach to the substrate in a vaporous state with a low flux density under conditions of ion-plasma sputtering, then these adhesive forces manifest themselves more actively than the forces of atomic interaction of gases. The paper proposes the following model for the formation of a nonequilibrium condensate on a substrate (Fig. 1). Let us conditionally single out a certain number of sputtered atoms $N$, the velocity of which in the direction of the substrate is $v$. Under the influence of adhesive forces, their density will change depending on the location relative to the substrate and will be a function of time: $n(\tau)$. Formally, the existence of an inverse function is also possible: $\tau(n)$. Let us determine the thermodynamic factor that will allow us to set the limiting size of the area of changed density in the classical form [9]:

$$
R_{k}=\frac{2 \sigma}{n_{1} \Delta \mu_{12}}
$$

where: $\sigma$ is surface energy; $n_{1}$ is the concentration of the new phase; $\Delta \mu_{12}$ is the change in the value of the chemical potential during the phase transition. This change can be written as follows:

$$
d \mu=-S_{a} d T+V_{a} d P
$$

where $S_{a}$ and $V_{a}$ are, respectively, the entropy and volume per atom of the substance.

\begin{tabular}{|c|c|}
\hline Fig. 1. Dependence of the change in the density of the condensate in the adhesion field of the \\
substrate (the field of action is $2-5$ nm).
\end{tabular}

In nonequilibrium conditions, $T$ and $P$ are functions of time, therefore, if $\tau(n)$, in equation (2) we can make the following transformations:

$$
\begin{gathered}
d \mu=-S_{a}(d T / d \tau)(d \tau / d n) d n+V_{a}(d P / d \tau)(d \tau / d n) d n, \\
d \mu=-S_{a}\left(v_{T} / \nu_{n}\right) d n+V_{a}\left(v_{P} / v_{n}\right) d n
\end{gathered}
$$


where $v_{T}, v_{n}, v_{p}$ are, respectively, the cooling rate, concentration change, and pressure change.

The change in the value of the chemical potential can be defined as a functional:

$$
\Delta \mu_{12}=\int v_{n}^{-1}\left(v_{p} n^{-1}-S_{a} v_{T}\right) d n
$$

where $n_{1}=V_{a}^{-1}$ is a new phase concentration.

Using relation (5), equation (1) is obtained in the form:

$$
R_{k}=\frac{2 \sigma}{n_{1} \int_{n}^{n_{1}} \frac{1}{\sqrt{n}}\left(\frac{v_{p}}{n}-S_{a} v_{T}\right) d n}
$$

The following analytical conclusions can be drawn from (6): the quantities $v_{T}, v_{n}, v_{p}$, $S_{a}, \sigma, n_{1}$ determine the critical limit, upon passing which the atoms are localized by the fluctuation mechanism and form regions with a new density and size larger than $R_{k}$. Under these conditions, the arising thermodynamic forces maintain the new state of this region. That is, this state becomes thermodynamically favorable, and the system also undergoes a phase transition. In this case, if the size of the fluctuation region with a new density is less than $R_{k}$, then the thermodynamic forces contribute to the disappearance of such formations. The new phase becomes thermodynamically disadvantageous, and the system will not experience phase transformations: that is, the condition of amorphization of the substance is satisfied. At the same time, the size of density fluctuations due to relaxation processes naturally has limitations. According to [6], the mean free path, which follows from the molecular kinetic theory with a correction factor $\varphi$, is:

$$
\lambda=\frac{\varphi}{\sqrt{2} \pi d^{2}\left(1+\frac{T_{c}}{T}\right) n}
$$

The free path $\lambda$ is a kinetic parameter that significantly affects the formation of an amorphous state (AS) of a substance, limiting the size of fluctuations; therefore, it is difficult to use it in equation (6). The largest size that a fluctuation can acquire cannot exceed $\lambda$. If this value is less than $R k$, then the general condition for amorphization, which includes all parameters affecting this process, has the form:

$$
R_{k}>\lambda
$$

In the case of a one-component system, this condition has the following form:

$$
\frac{2 \sigma}{n_{1} \int_{n}^{n_{1}} \frac{1}{\sqrt{n}}}\left(\frac{v_{p}}{n}-S_{a} v_{T}\right) d n>\frac{\varphi}{\sqrt{2} \pi d^{2}\left(1+\frac{T_{c}}{T}\right) n}
$$

Inequality (9) implies three most essential conditions for the influence of parameters on the formation of an amorphous state:

$$
\text { 1) } \left.v_{n} \rightarrow \infty \text {;2) }\left(\frac{1}{n} v_{p}-S_{a} v_{T}\right) \rightarrow 0 ; 3\right) \frac{T_{c}}{T} \rightarrow \infty
$$

These conditions are supported by experimental results: 1) if the energy and velocity of condensed atoms in the adhesion field of the substrate are increased, then condition (1) is satisfied and the tendency to amorphization of the substance increases; 2) 
with an increase in the values of $S_{a}$ and $v_{T}$, inequality (8) and condition (2) intensify, which will contribute to the amorphization process: thus, substances with a high evaporation temperature amorphized more easily than substances with a lower evaporation temperature; 3 ) lowering the substrate temperature decreases the temperature of condensed atoms and enhances the third condition for amorphization. However, there is a value of $v_{p}$, which is currently difficult for experimental determination, but its effect on the process of amorphization of a substance is also significant.

\section{Conclusions}

Through analyzing the above equations, the following conclusions can be drawn:

1) with an increase in the values of the parameters $v_{T}, v_{n}, S_{a}, \sigma, n_{1}, T_{c}, d$ and a decrease in $T, v_{p}, n_{1} / n$, the probability of the formation of an amorphous state increases.

2) active parameters of influence on the system for its amorphization are: $v_{T}, v_{n}, v_{p}$, $n$, and $T$. These values are basically determined by external factors: $v_{n}$ - kinetic energy of condensed atoms; $T$ - substrate temperature; $v_{p}$ - the rate of change in the pressure of the adhesive field; $n$ - steam pressure. The degree of activity of these parameters is determined by the ratio of internal and external factors.

3) passive factors of amorphization, which are determined by the type of substance, which do not depend on external conditions, are $S_{a}, \sigma, n_{1}, T_{c}, d$. These parameters determine the tendency of a substance to amorphization.

The listed factors and their effect on the amorphization process are in good agreement with the experimental results and contribute to the determination of further steps to obtain an amorphous state.

\section{References}

1. Dotsenko, F.F. Fizychni peredumovy formuvannya nadnerivnovazhnykh staniv ta otsinka skladu napylenykh splaviv / F.F. Dotsenko, V.F. Bashev // Visnyk Dnipropetrovskoho Universytetu. Fizyka. Radioelektronika. - 2001. - Vyp. 7. - S. 8-17.

2. Ma, E. Alloys created between immiscible elements / E. Ma // Progress in Materials Science. - 2005. - Vol. 50. - P. 413-509.

3. Bashev, V.F. Elektricheskiye svoystva i struktura W-Ba plenok v svezhenapylennom i ravnovesnom sostoyaniyakh / V.F. Bashev, F.F. Dotsenko, S.I. Ryabtsev // Fizika metallov i materialovedeniye. - 1995. - T. 80, № 1. - S. 117-123.

4. Dotsenko, F.F. Emissionnyye svoystva tonkoplenochnykh splavov iz nesmeshivayushchikhsya komponentov / F.F. Dotsenko, V.F. Bashev, S.I. Ryabtsev, A.S. Korchak // Fizika metallov i metallovedeniye. - 2010. - T. 110, № 3. - S. 237-242.

5. Bashev, V.F. Usloviya obrazovaniya metastabil'noy fazy vysokogo davleniya $v$ zhidkozakalennom samarii / V.F. Bashev // Fizika i tekhnika vysokikh davleniy. - 1998. - T. 8, № 1. - S. 93-96.

6. Gladkikh, N.T. Poverkhnostnyye yavleniya i fazovyye prevrashcheniya v kondensirovannykh plenkakh / N.T. Gladkikh, S.V. Dukarov, A.P. Kryshtal', V.I. Larin, V.I. Sukhov, S.I. Bogatyrenko. - Khar'kov: KhNU im. Karazina, 2004 - 276 s.

7. Komnik, Yu.F. Fizika metallicheskikh plenok / Yu.F. Komnik - Moscow: Atomizdat, 1979. - $263 \mathrm{~s}$.

8. Bashev, V.F. Physical properties and structure of vapor-quenched immiscible alloys / V.F. Bashev, N.A. Kutseva, A.I. Kushnerov S.N. Antropov, S.I. Ryabtsev // Journal of Physics and Electronics. - 2018. - Vol. 26, Issue 1. - P. 45-52.

9. Bazarov, I.P. Termodinamika / I.P. Bazarov. - St. Petersburg: Publishing house "Lan", 2010. - $384 \mathrm{~s}$. 